Archives de sciences sociales des religions

111 | juillet-septembre 2000

Varia

\title{
Des formes sensibles de la religion
}

Perceptible Forms of Religion

\section{Françoise Lautman}

\section{OpenEdition}

Journals

Édition électronique

URL : http://journals.openedition.org/assr/20215

DOI : 10.4000/assr.20215

ISSN : $1777-5825$

Éditeur

Éditions de l'EHESS

Édition imprimée

Date de publication : 1 septembre 2000

Pagination : 5-6

ISBN : 2-222-96695-7

ISSN : 0335-5985

Référence électronique

Françoise Lautman, "Des formes sensibles de la religion », Archives de sciences sociales des religions [En ligne], 111 | juillet-septembre 2000, mis en ligne le 19 août 2009, consulté le 01 mai 2019. URL http://journals.openedition.org/assr/20215; DOI : 10.4000/assr.20215

Ce document a été généré automatiquement le 1 mai 2019

(c) Archives de sciences sociales des religions 


\title{
Des formes sensibles de la religion
}

\author{
Perceptible Forms of Religion
}

\section{Françoise Lautman}

1 Les textes présentés ici sont pour la plupart issus d'une journée d'étude organisée dans le cadre de l'Association française de sociologie religieuse en juin 1996 sur ce même thème : formes sensibles de la religion. Cette date déjà relativement ancienne dit suffisamment que des études ont été complétées, que des approches alors programmatiques ont donné des fruits ; c'est le cas notamment pour Albert Piette dont l'ouvrage récemment paru La religion de près, l'activité religieuse en train de se faire (Métailié, 1999) met en œuvre les principes proposés dans ces pages. Le temps a été la cause également de ce que certaines participations ont trouvé d'autres tribunes; de jeunes chercheurs par contre se sont joints à nous.

2 Tous ont en commun la conviction que les religions ne relèvent pas seulement (ni peutêtre principalement) d'attachement à des valeurs, d'opinions, de façons de dire; elles constituent aussi (et peut être surtout) des façons de faire, des traditions festives, le goût de sonorités, d'éclairages, d'images... des préférences esthétiques, une affectivité... mais aussi des pratiques domestiques, relationnelles, des façons de se vêtir, de se nourrir, un rapport au corps... en un mot, des cultures! Ils ont préféré l'observation de comportements, la réflexion sur des productions, à l'interrogation des acteurs. Il nous semble que comprendre le mot « croire » comme l'expression d'une opinion ou l'adhésion à un corpus d'affirmations en est une approche intellectualiste qui ne correspond que partiellement à ce que signifie croire pour un croyant, le plus souvent peu conscient de ce qui est impliqué en tout cas dans les énoncés d'un Credo. Cela rend peu pertinentes des questions fondées sur des énoncés telles que « croyez-vous que Jésus-Christ est fils de Dieu » dont les réponses engagent des habitudes de langages et des stéréotypes autant qu'elles omettent toute référence à ce que peut signifier dans la culture actuelle « Fils de Dieu ». Pour le croyant, "croire» s'exprime autant, sinon plus, par des affects ou des pratiques que par des mots ; «croire » c'est prier (c'est-à-dire communiquer au delà du tangible), c'est s'interdire (des actes ou des choses défendues ou sacrées), c'est faire (des choses qu'on croit devoir ou qu'on croit efficaces), c'est craindre, c'est désirer... 
3 S'ils sont le fait principalement d'ethnologues ou d'historiens, les textes réunis ici ne veulent cependant en aucune façon prendre part à un manifeste, encore moins engager une polémique avec d'autres approches. Ils ne prétendent pas non plus aborder de façon systématique les points les plus propres à démontrer le bien fondé de nos positions de recherche. Ils se présentent en quelque sorte en ordre dispersé, au hasard de la rencontre entre nos terrains respectifs. Mais chacun met en évidence un questionnement dans lequel les autres reconnaissent leurs propres interrogations. Le « chef que l'on ne connaît pas ", dont on ne parle pas, mais qui se manifeste dans les éléments et dans le souffle de la vie, évoqué par André Julliard, renvoie à la difficulté d'exprimer toute expérience religieuse, fut-elle marginale ou marginalisée autrement que par l'emprunt à un vocabulaire codifié par les dépositaires de la légitimité religieuse, tout comme la transe dont parle Sossie Andézian. Tous deux mettent en évidence le caractère central du corps, de la santé, sur lequel se fonde une religion apparemment aussi éloignée des croyances africaines que l'antoinisme dont Anne-Cécile Bégot retrace l'évolution. À partir de leur terrain respectif, Laurence Hérault et Isabelle Saint-Martin parviennent à un même constat : celui de l'importance des activités sensorielles dans l'acquisition de l'expérience religieuse. Laurence Hérault observe l'apprentissage religieux par la pratique collective et commentée de la prière dans le cadre de deux cathéchèses, l'une catholique, l'autre protestante ; Isabelle Saint-Martin s'intéresse à l'enseignement catéchétique par l'image, notamment aux panneaux et aux grands cathéchismes en images édités au siècle dernier à l'intention des enfants ou des missions. L'impossibilité d'une pratique religieuse protestante qui soit le seul fait d'une transmission verbale abstraite telle que la prédication, apparaît aussi bien dans la dimension sensible des lieux, des objets et des gestes, inhérente à toute réunion, que dans le souci actuel des autorités religieuses d'en revaloriser les rites. Ce rôle déterminant des instances religieuses dans la légitimation $\mathrm{du}$ sensible est également démontré par Jean-Pierre Albert à propos de la mise en forme des lieux saints, sites de pèlerinages catholiques, dont la laideur fonctionnelle empêche toute sensibilité à leurs aspects naturels (faille, sommets, sources...) évocateurs de religion primaire, de paganisme. Enfin, tout en laissant à Albert Piette l'originalité de sa démarche dans son étude de l'activité religieuse en train de se faire et le caractère polémique de son argumentation, tous les auteurs ici rassemblés se reconnaissent dans le projet d'une observation rapprochée des formes ordinaires de la vie religieuse.

4 L'ethnologie s'est longtemps présentée comme la science de "l'autre », avec comme conséquence l'étude des faits religieux sous leurs formes exotiques, ou prétendues archaïques, ou encore déviantes, en tous cas aux marges des religions occidentales. Les auteurs se situent ici dans le fil d'une évolution qui reconnaît l'ethnologie d'abord comme science des cultures et s'ouvre à «l'ethnologie de soi ». Ils abordent résolument, mais avec difficulté, parfois seulement encore en esquisses qui demanderont, susciteront des recherches ultérieures, le cœur des pratiques chrétiennes; la régulation des lieux saints, la célébration, la transmission de la foi, la participation des fidèles à la vie courante des paroisses... 


\section{AUTEUR}

FRANÇOISE LAUTMAN

Groupe de sociologie des religions et de la laïcité 